\title{
A Case Study of College Students’ Acquisition of English Non-finite Words
}

\author{
Yuqing Xu \\ Department of Foreign Language Studies, Xiamen University Tan Kah Kee College, Zhangzhou, Fujian \\ 363105, China \\ xuyuqing@xujc.com
}

Keywords: non-finite verb, interlanguage, language transfer

\begin{abstract}
The use of non-finite words is one of the distinct differences between English and Chinese. How well do the Chinese students master English non-finite verbs? Are there differences between the good learners and poor ones in the mastery of English non-finite verbs? What are the difficulties and reasons affecting college English learners' acquisition of English non-finite words? Based on a placement test, the paper first analyses learners' mastery conditions of non-finite words. Then with theories of second language acquisition, the paper analyzes the difficulties and reasons affecting students' English non-finite verbs acquisition. Lastly, the paper gives some suggestions on English teaching and learning.
\end{abstract}

\section{Introduction}

English non-finite verb forms are complex. According to Oxford Dictionary of English Grammar [1], "Non-finite is a verb form or a clause without tense, the term is wider than infinitive, since it also covers the "-ing” form (e.g. looking, knowing) and the past participle (e.g. looked, known)". Unlike the finite verbs, which serve as the main verb in an independent clause, a non-finite verb cannot generally serve as the main verb in an independent clause and is not limited by the subject. It has no tense, person and number. There are four categories of English non-finite verbs: infinitive, gerund, present and past participle. Examples: 1) The man wanted to leave. 2) Leaving a beloved person is often very hard. 3) The woman was laughing heartily. 4) The glasses are wrapped in paper. As for ESL, the usage of non-finite verbs is difficult. The present paper tries to explore the mastery conditions of some non-finite verbs for freshmen, and tries to find out the problems lied in, by using with theories of second language acquisition.

\section{Research methodology}

\subsection{Study issues}

The issues are: 1) How well do freshmen master non-finite verbs? 2) Are there difficulties in the process of non-finite verbs acquisition? 3) Are there differences between the good learners and poor ones in the mastery of English non-finite verbs?

\subsection{Subject}

103 freshmen of non-English majors in Xia Men University were subjects in this study. Based on a College English Placement Test, 30 students are randomly sampled.

\subsection{Test tools}

The test consists of four parts: listening comprehension, reading comprehension, vocabulary and structure, and cloze. There are 45 questions for listening comprehension, 25 for reading comprehension, 35 for vocabulary and structure, and 20 for cloze, all the questions are multiple choice questions, which ensure the objectiveness and reliability of the results. The examinees can get one point for each question, the total score is 125 points. The present paper focuses on some non-finite verbs expressions in the vocabulary and structure part. After scoring, based on subjects' total scores, samples are divided into three groups: high group, medium group and low group, both 
high score students and low score students account for $27 \%$ of the total sample.

\subsection{Results and conclusions}

The paper chooses 3 questions from the vocabulary and structure part, which mainly test students' competence in non-finite verbs use.

1) Do you remember
A) to be introduced
C) introduced
B) being introduced
D) to have introduced to our president when you visited our school last month?

Question 1) aims at examining students' mastery of phrases used in the word "remember". In this question we know that the correct answer should be answer B), i.e., "Do you remember being introduced to our president when you visited our school last month?" The report shows that the difficulty index and the distinction rate are63.3\% and $61.7 \%$ respectively in this question. The difficulty index suggests there is a proportion-39.6 percent of students failed, that is to say most students have no difficulty in doing this question. The distinction rate indicates that there is a clear distinction between the high score and low score students. Therefore, this question is a significant one, to some extent, it successfully tests some acquisition of students' language competence in the word "remember".

The distribution of answers varies from high group students to low group students. In the high group, answers distributed mainly are B) and C), while there are answers A), B), C), and D) in the low group. In the high group, seven out of eight correctly chose the answer B), only one student chose the wrong answer $\mathrm{C}$ ). While in the low group, 2 chose A), 2 chose B), 1 chose C), and 3 chose D), only two out of eight answered correctly. When we investigated the performances of the two groups we find that high group students are more certain of using "-ing” form in the question than those of low group students. Therefore, for this question, there is a clear difference between high group students and low group students with respect to the mastery of English non-finite forms of the verb "remember". The good learners mastered the usage of non-finite verb "remember +-ing" form well, which means something happened already, while most poor learners cannot distinguish "remember+ -ing” from "remember + infinitive" expressions correctly.

2) It's a waste of time such matters.
A) discussing
B) to discuss
C) discuss
D) discussed

Question 2) is a useful expression, which tests students' mastery of the structure "It's a waste of time+-ing”. In this question, students are required to fill "discussing”. From the question we know that "discuss" is served as a non-finite verb in the sentence, it should follow "-ing" form after the word "time", the right answer should be A). The report shows that the difficulty index and the distinction rate are $63.3 \%$ and $24.7 \%$ respectively, that is to say, 63.3 percent of students chose the correct answer A). Among the high score students, six out of eight correctly chose the answer, while in the low score group, four out of eight correctly answered this question. The distinction rate (24.7\%) illustrates that there is a lack of apparent distinction between the good learners and poor learners. Besides, we find that most of the high group and low group subjects concentrate their choice on answers A) and B), few of them chose answer C) or D). This also shows that answer B), the infinitive form of "discuss", successfully interfere students' choice. Students have difficulty in choosing forms between "-ing” and infinitive in this question. Nonetheless, the high group students are more capable of inferring the right answer than the low group students.

3) Adam is so hungry success that he'll spare no efforts it.
A) at....achieving
B) at... to achieve
C) for...achieving
D) for...to achieve

The above question aims to test students' two language points, one is the usage of expression "be hungry for", the other is "spare time to do sth." The correct answer of this question is answer D), i.e., "Adam is so hungry for success that he'll spare no efforts to achieve it". The report shows that the difficulty index is $56.7 \%$ and distinction rate is $37.0 \%$ in this question. From the report data, we may judge this question is also a meaningful one since it examines some knowledge of subjects' 
linguistic ability to some extent, like preposition knowledge and verb forms knowledge. The difficulty index tells us over half of the subjects chose the correct answers, which indicates that is not a rather difficult question for most students. The distinction rate also effectively distinguishes good performers and poor ones.

The answer distribution of this question also varies from high group to low group. In the high group, answers distributed mainly are C) and D), while there are answers B), C), and D) in the low group. As for the proposition usage, high group subjects are more certain of the preposition use in the clause, they all answered correctly, while for the low group subjects, they failed to choose the correct one. As for the verb form of "achieve", both good learners and poor learners are unsure of the non-finite form of verb "achieve", there are three out of eight students in high group failed, while half students in the low group. Therefore, in this question, we may say high group subjects have a better mastery of the structure "spare time to do sth." than the low group ones. Also, high group students are more able to infer the right answer than low group students.

\section{Acquisition and error analysis}

The term 'interlanguage' was coined by the American linguist, Larry Selinker, the term first appeared in his thesis "Language Transfer" [3]. In 1972, he once again introduced the term 'interlanguage' in his article. According to Selinker, interlanguage refers to a unique linguistic system constructed by the foreign language learners in their process of learning, which is not only different from the learner's native language but also different from the target language. The nature of a learner's interlanguage is the learner's system of rules/assumptions/hypotheses about how the target language works. The learner's interlanguage may change over time and will get nearer and nearer to the target language, or become gradually more native-like.

Selinker identifies five principal cognitive processes responsible for second language acquisition: Language transfer; transfer of training (some interlanguage elements may derive from the way in which the learners were taught); strategies of second language learning; strategies of second language communication; overgeneralization of the target language material, some interlanguage elements are the result of a 'clear overgeneralization' of target language rules and semantic features [4].

Ellis considers that transfer is to be seen as a general term for a number of different kinds of influence from languages other than the L2. The study of transfer involves the study of errors (negative transfer), facilitation (positive transfer), avoidance of target language forms, and their over-use.

Firstly, negative transfer from Chinese may be a cause of students' errors. Good learners tend to suffer from negative transfer less. As far as Chinese students are concerned, English non-finite verbs are complex and difficult for they are very different from Chinese verbs, students need to pay attention to the forms, tense, aspect, etc. For example, there are seven out of eight in high group students chose the right answer "remember + being introduced" in the above question one, mainly because they know that it should be a perfect tense in the sentence first, meaning something happened already, then they know the perfect tense of "remember" is realized by the form of "remember + -ing". Knowing why and how, high group students therefore correctly chose the answer to the question. While for the low group students, most of them chose the answer "to have introduced", which can be explained that they also know that there should be a perfect tense in the question, but unlike the good performers who mastered the use of "remember + ing", they failed to use the correct perfect form. Their failure to distinguish the "remember + ing" form from "remember + infinitive" resulted in their wrong answer.

Secondly, facilitation (positive transfer) does not help much in students' acquisition of non-finite verbs since there are too many differences between their mother tongue and the target language.

Thirdly, avoidance of target language forms. Since English non-finite verbs are very different from Chinese, there is no form change of verbs in Chinese language, students tend to use verb stem in their speaking and writing, instead of using relatively complex non-finite forms.

Fourthly, overuse or overgeneralization, i.e., overgeneralizing grammatical rules, for example 
using “-ing” form to generalize all participles, or "to do" to generalize all infinitive forms, without paying attention to its tense, voice, purposes in the specific condition. For an instance, many low group even high group students used" achieving” in sentence "Adam is so hungry for success that he'll spare no efforts to achieve it.", it may be explained that some students overuse the structure of "spend time doing sth." so that they overgeneralize the use of similar structure of "spare efforts (time) doing sth.” in this case.

\section{Suggestions}

There are various strategies related to language learning, as far as the acquisition of English non-finite verbs are concerned, there are also some skills acquired through effective teaching and learning. Firstly, it can be improved through contrastive learning. Shuneng Lian [5] suggests that to master English, learners must learn about the features of the language; to get to know about the characteristics of this language, the most effective way of learning a foreign language is to compare it with native language. Take the usage of verbs for an example, there are distinct differences of verb forms, functions and tenses between the Chinese and English. Secondly, "grammar-consciousness" is an important way to acquire a language. Grammar-consciousness refers to awareness of grammatical correctness, paying attention to grammar use in a language while teaching and learning. Nowadays, grammar is often ignored by students even teachers while learning and teaching. It is very important to realize that grammar mastery is the essential part in learning a language well. Without the mastery of correct grammar, students cannot acquire a language precisely, so it is critical for students to pay attention to the rules used in the language. Last but not least, practice makes perfect. With more practice, learners may be easier to retrieve the accurate form of the language. Strategies like repetition, application of rules, imitation, and attention to detail in the use of language are also suggested. Practice can be done with the help of teachers but rely more on students themselves. What's more, students are expected to develop their own learning strategies while learning in order to achieve better effects. Only students cultivate an ability to evaluate their own learning process can they become active and effective in their learning. The best way is to help themselves.

\section{Conclusion}

Non-finite verbs are difficult and complex. From a freshmen's placement test, we find that students' competence of non-finite expressions varied from high group to low group students. For the good performers, most of them mastered some non-finite expressions well, like the usage of "remember doing sth.", "It is a waste of time doing sth." and "spare efforts (time) to do sth." While for most poor performers, they failed to master the usage of the language points examined in the test. In addition, high group students are more able to infer the correct answer than low group students when both of them are unsure of the right answers. Students' performances have some connection with their different levels of language acquisition. According to the SLA theory, learners tend to develop an interlanguage system in the process of learning, and they are influenced by language transfer, avoidance of target language use, and the overgeneralization of some language phenomenon, etc. Nonetheless, learners may get nearer and nearer to the target language with appropriate and effective learning strategies.

\section{References}

[1] Chalker Sylvia, Edmund Weiner. (2014) Oxford Dictionary of English Grammar. Shanghai Foreign Language Education Press, Shanghai.

[2] Selinker, L. (1972) “Interlanguage”. International Review of Applied Linguistics (10):209-31.

[3] Ellis, R. (1997) SLA Research and Language Teaching. Oxford: Oxford University Press, 359-362. 
[4] Wenden Anita, Joam Rubin. (1987) Learner strategies in language Learning. London: Prentice-Hall International English Language Teaching.

[5] Shuneng Lian. (1993) A Contrastive Study of English and Chinese Languages. Beijing: Higher Education Press. 